\title{
Formação de Conceitos em Crianças Cegas: Questões Teóricas e Implicações Educacionais ${ }^{1}$
}

\author{
Cecilia Guarnieri Batista ${ }^{2}$ \\ Universidade Estadual de Campinas
}

\begin{abstract}
RESUMO - A formação de conceitos depende da linguagem e do pensamento, que integram informações sensoriais. Postulase que mudanças no sujeito que conhece e nos objetos e eventos a serem conhecidos sugerem modelos flexíveis de ensino de conceitos. Considera-se que os mesmos pressupostos se aplicam ao ensino de conceitos a alunos cegos. São discutidas especificidades desse processo, incluindo o papel do tato como recurso, embora não como substituto direto da visão, e a noção de representação, como fundamento da elaboração de recursos didáticos para o aluno cego.
\end{abstract}

Palavras-chave: formação de conceitos; educação de cegos; desenvolvimento de cegos.

\section{Concept Formation in Blind Children: Theoretical Questions and Educational Implications}

\begin{abstract}
Concept formation depends on language and thought, that promote the integration of information coming from the senses. It is postulated that changes in the person, the objects and events to be known suggest flexible models of concept teaching. It is assumed that the same considerations apply to teaching concepts to blind pupils. Specificities of this process are discussed, including the role of touch as resource, although not as a direct substitute to vision, and the notion of representation as a basis for the elaboration of pedagogical resources for the blind student.
\end{abstract}

Key words: concept formation; blind education; blind development.

Uma das preocupações constantemente apresentadas por professores do ensino regular que recebem alunos cegos em suas classes refere-se ao modo de aprendizagem do aluno cego e, especialmente, aos recursos necessários para essa aprendizagem (Laplane \& Batista, 2003). A resposta reside, em parte, na adoção de recursos alternativos para acesso ao texto escrito, tais como o sistema Braille. Entretanto, ficam muitas dúvidas: Como a criança vai entender as noções apresentadas nas aulas? Como vai, por exemplo, fazer distinções entre animais? Conhecer o funcionamento do corpo humano? Compreender o que são acidentes geográficos?

De onde vêm essas dúvidas? Em parte, de uma concepção de aprendizagem centrada no aporte sensorial e, basicamente, na visão, conforme indicado na afirmação apresentada a seguir, a propósito da questão do ensino de artes para cegos: "Atestam as pesquisas mais recentes que os olhos são responsáveis por no mínimo $80 \%$ das impressões recebidas através da sensibilidade. Habitamos um mundo que se manifesta de forma predominantemente visual" (Oliveira, 1998, p.7).

1 Várias das idéias do presente texto foram desenvolvidas a partir de duas situações: encontros com professores da rede regular de ensino, realizadas em conjunto com a colega de trabalho Profa. Dra. Adriana Lia Friszman de Laplane; e discussões com a psicóloga e doutoranda em Psicologia Educacional, Maria Eduarda Silva Leme, que atua em reabilitação profissional e educação de jovens cegos. Este trabalho contou com o auxílio da FAEP-Unicamp: processo 1.534/2003.

2 Endereço: Universidade Estadual de Campinas, Faculdade de Ciências Médicas, Centro de Estudos e Pesquisas em Reabilitação, Rua Tessália V. de Camargo, 126, CP. 6111, Bairro Barão Geraldo, Campinas, SP, Brasil 13084-971. E-mail: cecigb@fcm.unicamp.br
Constata-se que, entre as falas dos educadores de cegos, são muito freqüentes as que se relacionam à busca de formas alternativas para apresentar objetos e eventos, que se assume serem conhecidos normalmente através da visão. Fica, entretanto, a questão: O que é conhecer? Ver é conhecer? Sentir sensorialmente é conhecer? Uma das respostas correntes na psicologia e no meio educacional relaciona o ato de conhecer à aquisição de conceitos. Propõe-se, então, no presente trabalho, discutir a questão da aquisição de conceitos, e suas implicações para o ensino de crianças cegas.

\section{Concepções sobre Conceitos}

A definição de conceito, no Dicionário Aurélio (Ferreira, 1975) apresenta nove itens, tendo o primeiro a seguinte acepção: 1. Filosofia: "Representação dum objeto pelo pensamento, por meio de suas características gerais." Nos demais itens do verbete, são apresentadas acepções relativas a: definição, idéia, concepção, opinião, avaliação e máxima ou provérbio. Assim, a primeira acepção, explicitamente, e as demais, de forma implícita, trazem a idéia de generalização, de busca do que há de generalizável em diferentes elementos, de modo a permitir identificações e agrupamentos sob o mesmo nome ou rótulo.

A psicologia vem se dedicando ao estudo dos conceitos, e, para isso, tem adotado diferentes concepções, dentre as quais foi considerada hegemônica, até recentemente, a chamada concepção tradicional ou clássica. Lomônaco, Caon, Heuri, Santos e Franco (1996), em uma revisão de literatura, apresentam quatro concepções presentes nas teorias de inves- 
tigação psicológica sobre conceitos: clássica, probabilística, dos exemplares e teórica.

\section{Concepção clássica}

A concepção clássica, cujas origens remontam ao realismo aristotélico, é apresentada por Medin e Smith (1984) como uma concepção que "sustenta que todos os exemplos de um conceito compartilham propriedades comuns, que se constituem em condições necessárias e suficientes para a definição do conceito" (p. 115). Medin (1989) dá como exemplo a categoria "triângulo", que atende aos critérios de possuir uma lista de propriedades individualmente necessárias e coletivamente suficientes para inclusão de uma figura geométrica nessa categoria. No caso do triângulo, os critérios são: ser uma figura geométrica fechada, possuir três lados e a soma de seus ângulos internos totalizar 180 graus. Essa concepção é também apresentada por Oliveira e Oliveira (1999), que destacam sua natureza binária, do tipo "tudo-ou-nada", de modo que "se duas entidades quaisquer são exemplares de um conceito, elas o são a igual título, ou seja, um conceito não se aplica mais ou melhor a uma entidade que a qualquer outra" (p. 18).

Lomônaco e cols. (1996) consideram que, embora a concepção clássica tenha sido predominante na psicologia por mais de meio século, várias dificuldades foram sendo evidenciadas. Essas dificuldades foram apresentadas por Medin e Smith (1984), a primeira sendo o fracasso na especificação de propriedades definidoras. Esses autores consideram que décadas de análises por lingüistas, filósofos, psicólogos e outros falharam na definição da maioria dos conceitos relativos a objetos. Uma outra dificuldade apontada refere-se à existência de casos cuja inclusão é incerta ou duvidosa, pois os limites das categorias não são delimitados com precisão. Como exemplo, Medin e Smith (1984) trazem a dúvida sobre se um tapete deve ser considerado como parte da mobília. Ainda outro argumento contra a concepção clássica refere-se ao fato de que alguns exemplos são mais típicos que outros. Nesse sentido, o conceito de ave seria melhor representado por uma andorinha ${ }^{3}$ do que por avestruz. Os autores citam, ainda, outros argumentos, também destacando a diferença de representatividade de diferentes exemplares colocados sob a mesma designação conceitual, e consideram que é o conjunto desses argumentos que acaba trazendo dificuldades para a concepção clássica.

A concepção clássica foi também criticada por Kitcher (1990), uma autora interessada nas contribuições de Kant para a psicologia, especialmente nas colocações do filósofo sobre conceitos empíricos. Kitcher faz uma crítica à visão clássica sobre conceitos, que supõe definições baseadas em condições necessárias e suficientes, e demonstra como Kant dá apoio a essa crítica. Afirma que, para Kant, os conceitos empíricos podem ser considerados como regras que nos permitem unir materiais que são apresentados separadamente à nossa percepção. Assim, conceitos empíricos são adquiridos, refinados, rejeitados, ou mantidos com base na experiência. Isso é o que os legitima: serem justificados ${ }^{4}$ pelo próprio

3 O exemplo original cita “robin”, cuja tradução seria "tordo", passarinho bastante comum nos EUA. processo que os produz e modela. Nesse sentido, dado que a experiência está permanentemente em aberto, eles não podem ser definidos por condições necessárias e suficientes.

Kitcher (1990) apresenta, ainda, duas outras implicações da crítica de Kant às definições de conceitos empíricos através de condições necessárias e suficientes (concepção clássica). A primeira ataca a noção de que a aprendizagem de conceitos ocorre em um período relativamente curto de tempo. Para ser coerente com a presente crítica, a aquisição de conceitos precisa ser concebida como uma experiência que continua ao longo da vida. A segunda implicação sugere que a própria noção de conceitos não seria adequada às mudanças no ambiente, e deveria ser substituída pela de protótipos conceituais, em constante mudança ao longo do tempo. Dessa forma, seria preservada a principal suposição teórica sobre conceitos empíricos: eles são centrais para a cognição por serem moldados pela experiência.

\section{Concepção prototípica ou probabilística}

A primeira alternativa à concepção clássica, segundo Lomônaco e cols. (1996), foi a concepção prototípica ou probabilística, proposta por Eleanor Rosch (Rosch, Simpson \& Miller, 1976). A autora afirmou ter se baseado em Wittgenstein, que sugeriu o princípio de semelhança entre categorias, formando famílias, de modo que cada item tivesse um ou mais elementos em comum com alguns outros, mas que nenhum elemento precisasse ser comum a todos os itens. Rosch sugeriu, então, a organização de categorias em torno de um conjunto de propriedades ou conjuntos de atributos correlacionados que são característicos ou típicos, rejeitando, assim, a noção de atributos definidores. Oliveira e Oliveira (1999) comentam que a concepção prototípica, da mesma forma que a clássica, identifica conceitos com conjuntos de propriedades. A diferença é que, nesse caso, as propriedades "constituem um protótipo, de tal maneira que a aplicabilidade de um conceito a uma entidade depende do grau de similaridade que existe entre a entidade e o protótipo do conceito" (p. 22). Assim, não se tem uma situação de enquadramento do tipo "tudo ou nada", mas de exemplares mais ou menos próximos do protótipo, com limites pouco definidos.

Entre as críticas a essa concepção, estão as de Medin e Smith (1984). Eles consideram que a mesma pode não captar adequadamente todo o conhecimento das pessoas sobre conceitos. Consideram que as pessoas, além de conhecerem propriedades características, também parecem conhecer o conjunto de propriedades de um conceito, bem como as relações entre elas, o que não estaria contemplado por essa concepção. Além disso, sugerem que essa concepção pode ser excessivamente aberta e flexível.

\section{Concepção dos exemplares}

A terceira concepção destacada por Lomônaco e cols. (1996) é a concepção dos exemplares, que guarda semelhanças com a concepção prototípica. Também se opondo à concepção clássica, esta concepção "assume que, pelo menos 
em parte, um conceito consiste em descrições separadas de alguns de seus exemplares" (Medin \& Smith, 1984, p. 118). Para eles, os modelos de exemplares têm em comum a idéia de que a categorização de um objeto se baseia em comparações daquele objeto com exemplares conhecidos da mesma categoria. Esses autores consideram como uma vantagem em relação à concepção prototípica o fato de que exemplares podem trazer informações sobre todo o conjunto de valores de uma propriedade, bem como informação sobre correlações entre propriedades. Criticam, por outro lado, o fato de se ter uma falta de restrições em relação a propriedades que devem ser incluídas em conceitos, ou mesmo, quanto ao que constitui um conceito.

\section{Concepção teórica}

A quarta e última concepção destacada por Lomônaco e cols. (1996), proposta como alternativa para superar as limitações acima apontadas, é a concepção teórica. Segundo esses autores, baseia-se na idéia de que, ao formar novos conceitos, o sujeito traz pressuposições sobre "como as coisas estão dispostas no mundo: como elas são, qual o seu modo de funcionamento e como se relacionam entre si. Estas pressuposições são denominadas 'teorias' ou 'modelos', (p. 53). É enfatizado o fato de que cada conceito se relaciona com outros conceitos, dentro de domínios de conhecimento, sendo cada domínio organizado por uma teoria, não necessariamente uma teoria científica. Murphy e Medin (1985) esclarecem que, quando argumentam que os conceitos são organizados por teorias, o termo "teoria" é usado para significar um grande número de "explicações" mentais, e não um relato científico completo e acabado. O termo indica "um conjunto complexo de relações entre conceitos, geralmente com uma base causal' (Murphy \& Medin, 1985, p. 290), de forma semelhante às teorias usadas em explicações científicas, embora não se confunda com estas. Lomônaco e cols. (1996) ressaltam a diferença dessa concepção em relação às demais, pelo fato de os conceitos passarem a ser vistos sempre como relacionados a outros conceitos, constituindo domínios de conhecimentos, articulados por teorias.

\section{Concepção defendida por Kitcher, baseada em Kant}

Depois de criticar a concepção clássica sobre conceitos, Kitcher (1990) traz a pergunta sobre os mecanismos mentais envolvidos em nossa habilidade de classificar com base em conceitos, já que foi rejeitada a noção das condições necessárias e suficientes. Lembra a sugestão de Kant quanto ao emprego de conceitos empíricos que se relacionem como gênero e espécie, entendendo-se "gênero" como categoria mais ampla, e "espécie" como subcategoria de "gênero". As características podem se coordenar entre si, ou constituir séries parciais de características hierarquizadas, que ascendem a gêneros mais altos e/ou descem para espécies mais baixas.

Segundo Kitcher (1990), Kant considera que essas relações de coordenação e subordinação não se constituem em uma "essência", mas apenas indicam relações de dependência entre as propriedades conhecidas a serem associadas ao conceito. Embora, pelos motivos já explicitados, não se possa ter uma lista completa das relações de dependência antes do "fim da ciência", existem alguns indicadores úteis. Conceitos demonstram a unidade sistemática que vai permitir a hierarquia de gênero e espécie quando um conceito de gênero indica: a) propriedades ou b) forças que governam, elementos que explicam os poderes ou propriedades do fenômeno indicado pelo conceito da espécie.

Kitcher (1990) considera que essa proposta de Kant é melhor que a concepção teórica de conceitos, pois não necessita da atribuição de teorias a crianças e adultos leigos. A heurística subjacente à teoria de Kant sugere a adoção de conceitos que indicam algumas relações de dependência entre atributos. Conceitos seriam apoiados apenas em fragmentos de teorias. A autora destaca, assim, as contribuições teóricas e heurísticas da visão de Kant sobre conceitos empíricos, que contesta frontalmente a concepção clássica e propõe uma alternativa à concepção teórica, especialmente quando não se trata de teorias científicas. Busca uma caracterização dos conceitos empíricos como inacabados, em processo de alteração, melhor caracterizados por relações parciais de dependência entre gênero e espécie, do que por sistemas fechados de definição por condições necessárias e suficientes.

\section{Conceitos em Piaget e Vygotsky}

Com um foco mais voltado para a aquisição, Piaget e Vygotsky também abordam a questão dos conceitos. Em relação a Piaget, é possível afirmar que, em sentido amplo, toda a sua epistemologia genética guarda relação com o tema “conceitos". Flavell (1975), autor de tradição piagetiana, discute a aquisição de conceitos em vários domínios: o mundo lógico e matemático (classes, relações e número), o mundo natural (objetos; quantidade - conservação de peso, substância e volume; espaço; tempo, movimento e velocidade; causalidade e conceitos afins) e o mundo social.

$\mathrm{Na}$ maioria desses domínios, Piaget representou um marco teórico e empírico, e sugeriu etapas, ou fases de evolução dos mesmos, ao longo da vida. $\mathrm{O}$ autor postulou que as aquisições humanas seguem estádios de desenvolvimento (Piaget, 1964/1967), com características bastante definidas. Esses estádios representam etapas ou marcos no desenvolvimento, a partir da primeira forma de inteligência, a sensório-motora, passando pelo início do uso do símbolo, das operações concretas e, finalmente, das operações formais. Sua epistemologia genética parte do modelo de conhecimento completo, presente no adulto, e se pergunta sobre a origem desse conhecimento, desde o início da vida do bebê. Busca as respostas por meio de investigações sobre as formas de construção de cada categoria de conhecimento, em cada estádio, propondo um modelo de desenvolvimento humano que seria classificado de organicista, de acordo com os critérios apresentados por Lewis (1999).

Por sua vez, Vygotsky (1934/1989) aborda a questão da aquisição de conceitos, fazendo distinção entre conceitos espontâneos e conceitos científicos, os primeiros adquiridos na experiência pessoal da criança, e os científicos, em sala de aula. $\mathrm{O}$ autor descreve etapas na formação de conceitos (sincretismo, complexo, conceito). Relata que, nos estudos realizados por seu grupo de pesquisa, o pensamento por conceito só foi observado a partir da adolescência, com gradual aparecimento dos verdadeiros conceitos e permanência das 
formas mais elementares em muitas áreas do seu pensamento. Traz um enfoque menos linear que Piaget, considerando que "a adolescência é menos um período de consumação do que de crise e transição" (p. 68). Sua abordagem ao processo de desenvolvimento pode ser classificada como contextualista, segundo os critérios de Lewis (1999). O autor dá ênfase ao papel da linguagem, ao considerar que o processo de formação de conceitos consiste em operação intelectual, "dirigida pelo uso das palavras como o meio para centrar ativamente a atenção, abstrair determinados traços, sintetizá-los e simbolizá-los por meio de um signo" (p. 70).

Vygotsky (1934/1996) critica a noção da psicologia tradicional, baseada na lógica formal, de que o conceito é uma estrutura mental abstrata, muito distante de toda a riqueza da realidade concreta. Ao invés disso, afirma que O verdadeiro conceito é a imagem de uma coisa objetiva em sua
complexidade. Apenas quando chegamos a conhecer o objeto
em todos os seus nexos e relações, apenas quando sintetizamos
verbalmente essa diversidade em uma imagem total mediante
múltiplas definições, surge em nós o conceito. (Vygotsky,
1934/1996, p. 78)

Ao longo da presente revisão sobre concepções relativas a conceitos, destaca-se a tendência por visões dinâmicas, adequadas à captação de uma realidade mutável e multifacetada. A partir das mesmas, são sugeridas as seguintes decorrências para o processo educacional:

a) Com base na concepção teórica, conceitos vistos como relacionados a outros conceitos, são organizados em sistemas, que variam de acordo com teorias e objetivos específicos. Desse modo, o mesmo elemento a ser conceituado pode fazer parte de diferentes sistemas conceituais, não existindo, portanto, uma definição única e exclusiva para um determinado conceito (ex: "cachorro" tem uma definição enquanto componente do sistema de classificação dos seres vivos pela Biologia, outra no âmbito da discussão sobre animais de estimação, e outra, ainda, como possível vetor de doenças).

b) A partir das colocações de Kitcher (1990), uma proposta de caracterização de conceitos empíricos como relações entre "gênero" e "espécie", de modo aberto, ao invés de definições fechadas, por condições necessárias e suficientes.

c) Também a partir de Kitcher (1990), a noção de que a aquisição de conceitos deve ser concebida como uma experiência que continua ao longo da vida, não podendo ser pensada, exclusivamente, como aprendizagem a curto prazo.

d) Com base nas colocações de Vygotsky (1934/1989, 1996), uma concepção de aquisição de conceitos voltada para processos de mediação por signos, particularmente a mediação pela linguagem, e, assim, colocando o foco nas interações entre pessoas, objetos e situações, como integrantes ativos de contextos sociais e culturais, ao longo do processo contínuo de apropriação do significado de conceitos.

Tendo em vista essas considerações, fica claro que o mesmo objeto pode ser conceituado em diferentes níveis, dependendo de diferentes fatores. Além da questão evolutiva, abordada pelos teóricos do desenvolvimento, é importante salientar que, ao longo da vida, as pessoas se envolvem em diferentes tipos de interação, que levam a diferentes níveis de aprofundamento de diferentes conceitos. Assim, ao longo das experiências de uma pessoa, e dos conhecimentos que adquire, muda o nível de compreensão de cada conceito. Por exemplo, o conceito de Poder Legislativo é diferente para uma criança de 8 anos, um adolescente que fez uma visita a uma Casa Legislativa, um adulto que trabalha como escriturário em uma Câmara de Vereadores, um deputado, um leitor assíduo de jornal e um cientista político. O mesmo pode ser pensado em relação a quaisquer outros exemplos, tais como, "casamento", "maternidade e paternidade" ou "carreira profissional".

É importante lembrar, também, que as coisas a serem conceituadas (objetos, eventos, instituições, costumes) estão em mudança, o que é mais acentuado em uma sociedade tecnológica como a atual. Entre outros exemplos, podem ser mencionadas as alterações recentes no conceito de "telefone": os modelos com fio e sem fio, os conjugados a aparelhos de fax e secretária eletrônica, e os celulares, com suas múltiplas funções. Outros exemplos: TV tradicional versus interativa; teatros tradicionais versus Centros Culturais; os computadores pessoais dos anos 1980, os dos anos 1990, e os atuais notebook e palmtops. Observam-se, ainda, alterações nos significados das palavras, alterações mais rápidas e efêmeras na gíria, mas também observadas nas formas cultas da língua e nas variações dialetais.

Assim, ao longo da vida, o processo de aquisição vai assumindo formas cada vez mais individualizadas e típicas de pessoas e de grupos: mudam as coisas, muda o nível de conhecimento das coisas, definem-se áreas de domínio conceitual preferencial (dependendo, entre outros fatores, da atividade profissional e de interesses pessoais). Não tem sentido, portanto, falar em "conceito adquirido" em situação escolar como algo definitivo.

\section{Aquisição de Conceitos por Pessoas Cegas}

A questão da aquisição de conceitos por cegos passa, em primeiro lugar, por tudo o que se refere à aquisição de conceitos por qualquer pessoa, com ou sem alterações sensoriais. Aplicam-se, portanto, as observações e conclusões apresentadas anteriormente, acrescidas de tópicos específicos relativos ao tema. Nesse sentido, será apresentada uma breve revisão sobre aquisições de pessoas cegas, e apresentados e discutidos os resultados de um levantamento sobre concepções de professores a respeito do ensino de conceitos para alunos cegos. Serão discutidos, a seguir, as questões centrais destacadas nesse levantamento, a saber, o uso do tato como recurso no ensino de cegos e a noção de representação no planejamento de material didático para cegos.

\section{Aquisições de pessoas cegas}

Estudos recentemente realizados no Brasil mostraram exemplos de competências dos cegos na aquisição de conceitos. Leme (1999) investigou a compreensão do significado de palavras que se supõe terem uma base visual (como "arco-íris" e "transparente"), em relação a quatro 
adolescentes do sexo feminino com cegueira congênita. Os resultados indicaram significados corretos para a maioria das palavras, para quase todas as jovens, em geral com alto grau de generalização e abstração das respostas.

Passos (1999) estudou a compreensão de metáforas por dois meninos cegos congênitos, com idade entre 12 e 13 anos. A intervenção envolveu a explicação do significado de algumas das metáforas. Os resultados indicaram que os dois meninos mostraram aumento na compreensão das metáforas cujo significado foi explicado, e também para as metáforas não explicadas, embora com diferenças no nível de desempenho entre eles.

Ormelezzi (2000) pesquisou a aquisição de representações mentais por cegos adultos. Constatou que a formação de imagens e conceitos dos participantes se dava pelas experiências de tipo tátil, auditiva e olfativa, inter-relacionadas com a linguagem das pessoas com quem interagiam. E, no caso de conceitos pouco ou nada acessíveis à percepção, verificou significados consistentes, cuja aquisição foi atribuída à linguagem.

Nunes (2002) propôs o ensino de quatro grupos de conceitos (coisas tateáveis pequenas, coisas tateáveis grandes, conceitos não tateáveis e conceitos abstratos), para três crianças cegas com idades entre 9 e 10 anos. Os resultados indicaram que todos os participantes apresentaram desempenho apreciavelmente melhor após a intervenção.

Nunes (2004) apresentou seis histórias (elaboradas por Keil, centradas na concepção teórica de conceitos, e adaptadas para o Brasil por Lomônaco) para sete crianças cegas entre 8 e 13 anos. Verificou que as crianças basearam-se, na maioria das vezes, em atributos definidores, considerados superiores aos atributos característicos. Também solicitou aos sujeitos a definição de 15 conceitos, concretos e abstratos, e analisou as categorias de respostas. Dessa forma, identificou formas diferenciadas de definição e de utilização de recursos perceptivos para a elaboração dos conceitos.

Quanto à literatura internacional, a recente revisão de Nunes (2004) buscou as principais bases de dados, no período de 1980 a 2004. A autora encontrou um número relativamente pequeno de estudos, a maioria publicada no Journal of Visual Impairment and Blindness. A tendência geral dos resultados foi de indicar capacidades conceituais dos cegos, semelhantes às dos videntes, sendo as diferenças discutidas como relacionadas a modos alternativos de processamento cognitivo das informações sensoriais.

De modo geral, as revisões mais recentes sobre o desenvolvimento de pessoas cegas (Lewis, 2003; Warren, 1994) não trazem mais a dúvida sobre presença de capacidades, e sim, questionamentos sobre aspectos em que diferem, e implicações teóricas e práticas dessas diferenças.

De uma forma abrangente em relação às capacidades dos cegos, com implicações para o tópico em questão, Warren (1994) critica o que ele denomina de abordagem comparativa ao estudo dos cegos, em que capacidades e características de crianças cegas são avaliadas em relação às capacidades correspondentes de crianças videntes, sempre em relação à idade cronológica. $\mathrm{O}$ autor afirma ter utilizado essa abordagem em seus livros anteriores de revisão da literatura sobre o desenvolvimento de crianças cegas. E propõe, como alternativa, a abordagem diferencial, definindo-a como busca da explicação de diferenças dentro de uma população, com principal atenção para os casos de alta aquisição. Warren (1994) considera que um caso de alta aquisição nos diz mais que a informação sobre resultados médios, pois já é suficiente para indicar que as possíveis dificuldades não são inerentes à cegueira, e, ao mesmo tempo, instiga à identificação dos processos que favoreceram essas aquisições. $\mathrm{O}$ autor critica propostas de aconselhamento de pais e profissionais, que descrevem aquilo que, "em média", uma criança cega pode adquirir, por acreditar que tendem a reduzir expectativas de aquisição. Essas colocações de Warren sugerem novas formas de investigação, e colocam sob suspeita os estudos comparativos que concluem sobre incapacidades ou atrasos na aquisição de diferentes habilidades por cegos, incluindo a questão de conceitos.

Por sua vez, Lewis (2003) apresenta revisão de literatura sobre o desenvolvimento de crianças cegas, concluindo que a cegueira não impede o desenvolvimento, mas que este difere, de diversos modos, do apresentado pelas crianças videntes. Considera, assim, que o estudo de crianças cegas pode ser significativo para as teorias de desenvolvimento, e sugere três implicações teóricas desses estudos. A primeira se refere à necessidade de identificação de rotas alternativas de desenvolvimento. Lewis (2003) argumenta que, se as crianças cegas apresentam uma quantidade relativamente pequena de problemas de desenvolvimento, isso indica que este pode ocorrer na ausência do input visual. E aponta a linguagem como a principal fonte de informação para a criança cega, e possível substituto para muito do que ela perde pela falta de visão. Em relação a esse tópico, considera-se que cabe uma discussão sobre relações entre input sensorial e processos cognitivos, que remete à pergunta epistemológica sobre a origem do conhecimento. Hessen (1925/2000), em texto clássico publicado no início do século $\mathrm{XX}$, apresenta e discute possíveis respostas a essa pergunta, colocando as posições do empirismo e racionalismo clássicos, o primeiro enfatizando o papel dos sentidos, o segundo, a importância da razão. O autor também apresenta como formulações mais recentes, representando tentativas de conciliação: o intelectualismo, mais próximo do empirismo, e o apriorismo, mais próximo do racionalismo. A discussão continua, e o que importa enfatizar é que não se concebe mais o empirismo ou racionalismo puros. No mesmo sentido, embora com grandes variações, a Psicologia tende a pensar no conhecimento como fruto de interação entre informações provenientes dos sentidos e processos cognitivos, em que a linguagem assume papel relevante, embora com variações nos diferentes quadros de referência teórica. Assim, quando Lewis fala na linguagem como possível substituto do que a criança cega perde pela falta de visão, é importante lembrar que a linguagem é importante para qualquer pessoa, e que é difícil falar em um único substituto para a visão. $\mathrm{O}$ que se coloca, no caso do cego, é a pergunta sobre como se organizam e se integram as informações provenientes dos sentidos remanescentes, e qual o papel da linguagem e do pensamento nessa organização.

A segunda implicação teórica apresentada por Lewis (2003) refere-se à busca de explicações para problemas no desenvolvimento de crianças cegas, nos casos em que aparentemente não existem problemas cerebrais que os justifiquem. Sugere que essas crianças podem não ter recebido, ao longo de seu desenvolvimento, inputs apropriados em quantidade, 
qualidade ou variedade, de modo a permitir convergência de informações e redundância das mesmas. A autora aponta, portanto, para a importância de se investigar influências ambientais, ao longo da história do desenvolvimento da criança, deslocando o foco do limite orgânico, como fator único de produção de dificuldades.

A terceira implicação refere-se às teorias evocadas para explicar diferenças observadas. Lewis (2003) discute o fato de que a teoria de Piaget prevê relações entre o aparecimento de diferentes manifestações (ex: reação à separação dos pais, noção de permanência de objeto, linguagem, compreensão de causalidade e jogo), como reflexo da habilidade subjacente de representação mental do ambiente. Lembra exemplos de estudos com crianças cegas, em que foram observadas discrepâncias entre essas manifestações, estando algumas atrasadas e outras ocorrendo no mesmo período que para as crianças videntes. $\mathrm{E}$ as discute sugerindo a necessidade de formulações teóricas que não sejam baseadas apenas no estudo do desenvolvimento de crianças videntes. Cabe comentar que a teoria de Piaget não é a única que discute o desenvolvimento infantil, e que se trata de uma teoria que seria classificada por Lewis (1999) como organicista, com ênfase no estabelecimento de etapas claramente delimitadas no desenvolvimento. Lewis (1999) discute a questão das abordagens ao desenvolvimento infantil e critica modelos de desenvolvimento que ele denomina organicistas. Propõe que os mesmos sejam substituídos por modelos contextualistas de desenvolvimento, que enfatizam: a) a descontinuidade no desenvolvimento, opondo-se à noção de continuidade; b) uma visão da criança como participante ativo de sua socialização e desenvolvimento, contrapondo-se a uma visão passiva, dependente de imperativos biológicos e do ambiente social; c) uma concepção da história do desenvolvimento como narrativa, como representação de eventos passados passível de reconstrução, oposta à noção de história como fotografia. Assim, com relação às colocações de Lewis (2003), considera-se que são bastante relevantes quando sugerem que as formulações teóricas sobre desenvolvimento não sejam baseadas exclusivamente no estudo de crianças videntes. Entretanto, não apenas porque as explicações não se coadunam com as colocações da teoria de Piaget sobre estágios de desenvolvimento, mas também porque outros modelos podem ser propostos para o estudo do desenvolvimento de todas as crianças, com ou sem alterações orgânicas.

Verifica-se que diferentes autores, sob diferentes perspectivas, trazem dados sobre as possibilidades de desenvolvimento de crianças cegas e buscam elucidar processos de aquisição, enfatizando a contribuição de fatores ambientais e apontando implicações teóricas e metodológicas do estudo dessas crianças.

\section{Concepções de professores sobre ensino de conceitos para cegos}

Abordando-se a questão de outro ângulo, o dos professores em sala de aula, pode-se perguntar o que eles pensam sobre o ensino de crianças cegas, especialmente quando está em implantação a política de inclusão de alunos com deficiência no sistema regular de ensino. Um estudo foi realizado por Laplane e Batista (2003), com 25 professoras do ensino regular (pré-escola e primeiras séries do Ensino Fundamental) que tinham alunos com deficiência visual em suas classes, em municípios do interior de São Paulo. Foram identificadas e discutidas algumas de suas crenças sobre o planejamento de ensino para esses alunos, sistematizadas em quatro categorias, apresentadas a seguir.

1) A discriminação tátil constitui-se em habilidade básica, que deve ser bem treinada em crianças cegas.

Considera-se, assim, o tato como a principal forma de obtenção de informação para o cego. Sugere-se que o tato deve ser treinado extensivamente na discriminação de diferentes materiais e de diferentes aspectos desses materiais, tais como forma, textura e peso. Muitas vezes, essas atividades são propostas de forma de exercícios específicos, com amostras variando ao longo de uma dimensão, como forma ou textura, a serem discriminadas fora de contextos significativos. Revivem, assim, a estratégia pedagógica do exercício de habilidades isoladas, que tem sido bastante criticada pela pedagogia contemporânea.

2) O que não é apreendido pelos olhos, deve ser ensinado por meio de modelos táteis.

As professoras demonstram grande preocupação com a falta de material adequado, e parecem crer que esses recursos táteis, per se, permitiriam as aquisições de conhecimento pelos alunos cegos. As autoras do estudo discutem a crença subjacente a essa afirmação, de que a formação de conceitos depende, basicamente, de informações primárias, provenientes dos sentidos, e de que o tato é o principal substituto da visão.

3) Deve-se oferecer à criança cega uma grande quantidade de objetos, que a ajudarão a construir conceitos.

As professoras pensam que deveria ser usada uma profusão de objetos, em tamanho real ou miniatura, e assumem que o ensino vai ser mais efetivo, quanto mais objetos forem oferecidos. As situações não facilmente apresentáveis ao tato provocam dúvidas e insegurança quanto à possibilidade dos alunos de ter acesso a esses conhecimentos, incluindo: a) elementos não facilmente miniaturizáveis, e/ou que perdem muitas de suas características nessa situação. Exemplos: conjunto de edifícios, acidentes geográficos (lago, montanha, etc); b) elementos que são inacessíveis ao toque, como bolha de sabão, fenômenos atmosféricos (nuvem, raio, arcoíris), entre outros; c) elementos que são perigosos ao toque: animais agressivos ou peçonhentos, objetos quentes, etc; d) elementos cujo toque é proibido ou pouco convencional, como é o caso de certas partes do corpo, certos animais (sapo), entre outros.

A idéia é que se deveria ter um acervo, o mais completo possível, de objetos, miniaturas e ampliações. Lamenta-se a impossibilidade de o cego ter acesso aos elementos não reprodutíveis em modelos tateáveis. As autoras do estudo consideram que a questão a ser discutida é a da representação, e levantam as seguintes questões: Será que todo objeto representa a noção que se pretende trazer para o aluno? Que preocupações deveriam estar presentes, ao se planejar um objeto como representante de outro objeto ou fenômeno?

4) Representações visuais devem se converter em representações táteis, para ensejar a formação de conceitos.

Aqui, as professoras se referem, principalmente, a representações bidimensionais: figuras, fotografias, desenhos, mapas, esquemas. No caso do aluno cego, alguns recursos já foram desenvolvidos, e muito resta a fazer. Há questões 
importantes a discutir, para balizar a elaboração desses recursos. Nesse sentido, Masini (1994) retoma formulações de Chauí que, em obra sobre "o olhar", conclui que conhecer não é ver, mas que o ver permanece como condição para o conhecer. Masini comenta que, no caso, "se está falando da 'maioria' dos seres que aí estão, existindo como videntes e percebendo pela predominância da visão sobre os demais sentidos" (p. 81). E lança a pergunta: "Não seria possível pensar de uma outra maneira? (...) Porque não perguntar como é o pensar daquele que aí está e não é vidente?" (p. 81). Nesse sentido, a autora analisa e critica "propostas, instrumentos e fundamentações para trabalhos com o D.V., cujo referencial básico era exatamente o que não é próprio dele, isto é, a visão" (p. 75).

Considera-se, assim, que a partir da pesquisa de Laplane e Batista (2003), emergem questões relativas ao papel do tato no ensino do cego e à noção de representação no planejamento de recursos didáticos.

\section{O uso do tato como recurso no ensino de cegos}

Dentre os autores que discutem a questão do papel do tato para o cego, destacam-se Ochaita e Rosa (1995), que apresentam o sistema háptico ou tato ativo como o sistema sensorial mais importante para o conhecimento do mundo pela pessoa cega. Para esses autores, é necessário diferenciar entre tato passivo e tato ativo ou sistema háptico. Enquanto no primeiro a informação tátil é recebida de forma não intencional ou passiva, no tato ativo a informação é buscada de forma intencional pelo indivíduo que toca. Assim, segundo eles, no tato ativo encontram-se envolvidos não somente os receptores da pele e os tecidos subjacentes (como ocorre no tato passivo), mas também a excitação correspondente aos receptores dos músculos e dos tendões, de maneira que o sistema perceptivo háptico capta a informação articulatória, motora e de equilíbrio.

Ainda segundo Ochaita e Rosa (1995), existem importantes diferenças entre a percepção e o processamento da informação mediante o tato e a visão. Afirmam que a captação da informação mediante o tato é muito mais lenta que a proporcionada pelo sistema visual, e lembram que essa informação tem caráter seqüencial. Consideram que isto dá lugar a uma maior carga na memória de trabalho, quando os objetos a serem explorados são grandes ou numerosos (exemplo: exploração tátil de uma mesa, em comparação com sua exploração visual). Além disso, enquanto o tato somente pode explorar as superfícies situadas no limite que os braços alcançam, a visão é o sentido útil por excelência para perceber objetos e sua posição espacial a grandes distâncias.

Assim, o tato constitui um sistema sensorial que tem determinadas características e que permite captar diferentes propriedades dos objetos, tais como temperatura, textura, forma e relações espaciais. Essa captação tem caráter seqüencial e funciona a curta distância, correspondendo ao alcance da mão. Ao mesmo tempo, difere da visão, que permite a obtenção de informação simultânea e à distância.

Outros autores que escrevem sobre a cegueira também exaltam o caráter totalizador ou global da visão. Ferrell (1996) dá o exemplo de como uma criança passa a conhecer um gato: ao explorar o animal, a criança toca sua cabeça, corpo, pernas, sente suas garras, percebe a maciez do pelo, ouve seus miados, sente seu cheiro e, ao mesmo tempo, está sempre vendo a imagem do gato todo. A autora afirma que isso é diferente do caso da criança cega, que pode passar por várias experiências isoladas (ouvir um miado, tocar uma parte do corpo do gato, levar um arranhão, entre outras) sem ter a facilidade de integrar todas essas experiências como provenientes de um gato.

É inegável o papel da visão ao trazer informações sobre elementos colocados em diferentes distâncias, possibilitando percepção global e noção de profundidade, bem como a análise dos elementos que compõem a cena. Entretanto, podem ocorrem dois tipos de erro ao se valorizar o papel da visão: um é o de confundir o papel da percepção visual global com o dos processos mentais superiores na compreensão de conceitos; outro, é o de subestimar o valor de informações sequienciais. Em relação ao primeiro aspecto, é importante lembrar o que já foi destacado sobre aquisição de conceitos. Aplicando essas considerações ao exemplo do gato, uma criança não vai ter a noção de gato por ver um gato, mas por integrar dados sensoriais e explicações verbais que lhe permitam identificar e descrever um gato, estabelecer distinções entre gato, cachorro e rato, e, no processo de educação formal, adquirir noções cada vez mais profundas e complexas sobre seres vivos e suas propriedades.

Quanto ao segundo ponto, sobre o valor das informações seqüenciais, é oportuno lembrar que, na vida, estão presentes muitas modalidades de informação seqüencial: a música, o texto longo (romances, dissertações, entre outros), a exibição de um filme ou de uma peça de teatro. Nesses casos, não se considera que haja perdas ou dificuldades, pela impossibilidade da captação global e simultânea de todos os elementos que vão sendo apresentados em seqüência.

Ainda um outro aspecto, em geral pouco ressaltado, é o fato de que videntes se baseiam muito mais em informações conjugadas a partir de vários sentidos, do que unicamente na visão. Às vezes, tarefas são descritas como basicamente visuais, quando não é o caso, pois vários sentidos participam da mesma, além, é claro, do papel predominante dos processos cognitivos. Podem ser citadas várias situações em que é clara a participação do tato e do sentido proprioceptivo, além da visão: localizar objetos em uma bolsa; acionar equipamentos com teclas, como telefone, teclado de computador, ou controle remoto; tocar instrumentos; vestir-se (lembrar de como se coloca um cinto nos passadores ou se puxa um zíper nas costas); localizar alguns dos comandos de um carro, especialmente os dos pés. Assim, reitera-se que, para um cego, não se trata de substituir a visão por outros sentidos, normalmente inativos, mas de acioná-los de uma forma diferente do vidente, que parece usar a visão para "guiar" os demais sentidos. O tato constitui-se em recurso valioso no ensino de alunos cegos. Entretanto, não pode ser visto como substituto da visão, nem pensado de forma independente dos processos cognitivos envolvidos na apropriação de conhecimentos.

\section{A noção de representação no planejamento do material didático para cegos}

Uma representação pode ser entendida como um elemento colocado no lugar de outro. Em sala de aula, professores 
lançam mão de representações para trazer alguns dos elementos do mundo, relevantes para determinada explicação. Quando se trata do ensino de videntes, para os quais já existe uma longa tradição bem estabelecida, os professores utilizam meios bidimensionais (gravuras, fotos, esquemas, mapas, filmes) e tridimensionais (objetos reais ou miniaturas). Muitas convenções vêm sendo estabelecidas, de tal forma que, algumas vezes, deixa-se de entendê-las como convenções. É o caso, por exemplo, dos esquemas (ex: célula, átomo, sistema solar) e dos mapas, que parecem auto-evidentes para os iniciados em sua interpretação. No caso de gravuras, é importante lembrar as convenções para indicar formas, incidência de luz, texturas e distâncias relativas, que vão mudando ao longo da história da arte e da história do desenho pedagógico e das ilustrações infantis.

Uma vez que se trata de representações, a tarefa, em relação ao aluno cego, é de buscar as melhores formas de representação para esse aluno. É um desafio interessante para o professor, paralelo ao trabalho de estabelecer representações para o aluno vidente, embora mais instigante e criativo, devido à menor oferta de modelos disponíveis. Dessa forma, começam a ser equacionados os problemas explicitados pelas professoras na pesquisa anteriormente mencionada, em relação a formas de trazer "o mundo" (objetos, veículos, acidentes geográficos, animais peçonhentos) para a sala de aula. Assim, a diferença entre alunos videntes e cegos fica centrada nos modos de representação a serem utilizados como auxiliares na explicação de diferentes conceitos, o que é mais promissor que a discussão centrada na constatação das dificuldades trazidas pela cegueira, sempre comparadas com a ausência dessas dificuldades nos videntes.

Um exemplo refere-se à compreensão da idéia de "trem com 45 vagões". Para tanto, é necessário saber o que é trem, vagão e ter noção de número. Trata-se de vários conceitos, cuja aquisição envolve múltiplas situações de ensinoaprendizagem, tanto no caso do aluno cego, como do vidente. No caso do aluno cego, não é preciso, como freqüentemente postulado, levá-lo a percorrer um trem com esse número de vagões ou apresentar-lhe uma miniatura desse trem. A oferta de recursos pedagógicos para o ensino do conjunto de conceitos envolvidos na referida expressão dependerá dos conhecimentos anteriores do aluno, e não se dará em uma única aula. Outro exemplo refere-se ao conceito de relâmpago, em séries mais avançadas do ensino. Nesse caso, as explicações envolvem noções de eletricidade, dispensando-se o uso de recursos tangíveis, ou a capacidade de ver um relâmpago, como requisito para compreensão.

\section{Conclusão}

Concepções recentes sobre conceitos apontam para processos de mudança, interação entre elementos e relatividade de sistemas de classificação. Mudanças se referem tanto ao sujeito que conhece como aos objetos e eventos a serem conhecidos. Essas concepções sobre conceitos apontam para a importância dos processos cognitivos, especialmente linguagem e pensamento, na elaboração e integração das informações provenientes dos sentidos.

No que se refere ao ensino de conceitos para alunos cegos, as decorrências dessas concepções devem ser levadas em conta, da mesma forma que para alunos videntes. A especificidade fica por conta da elaboração de recursos auxiliares na compreensão de diferentes conceitos e sistemas de conceitos. Para tanto, é relevante redefinir o papel do tato, como importante recurso, embora não como substituto direto da visão. É também relevante pensar a noção de representação, como base para o planejamento de recursos didáticos, a serem elaborados e apresentados de forma interligada aos sistemas conceituais já adquiridos e em fase de aquisição pelos alunos.

\section{Referências}

Ferreira, A. B. H. (1975). Novo dicionário Aurélio. Rio de Janeiro: Nova Fronteira.

Ferrell, K. A. (1996). Your child's development. Em M. C. Holbrook (Org.), Children with visual impairments: A parents' guide (pp. 73-96). Bethesda: Woodbine House.

Flavell, J. H. (1975). O desenvolvimento de conceitos. Em P. H. Mussen (Org.), Carmichael: Psicologia da Criança. (M. H. S. Patto, Trad.) (pp. 1-130). São Paulo: EPU, EdUSP.

Hessen, J. (2000). Teoria do conhecimento. ( $2^{\mathrm{a}}$ ed.). São Paulo: Martins Fontes. (Originalmente publicado em 1925).

Kitcher, P. (1990). Kant's transcendental psychology. New York \& London: Oxford University Press.

Laplane, A. L. F. \& Batista, C. G. (2003). Um estudo das concepções de professores de ensino fundamental e médio sobre a aquisição de conceitos, aprendizagem e deficiência visual [Resumo]. Em Associação Brasileira de Pesquisadores em Educação Especial (Org.), Anais do I Congresso Brasileiro de Educação Especial, IX Ciclo de Estudos sobre Deficiência Mental, (pp. 14-15). São Carlos: UFSCar.

Leme, M. E. S. (1999). Investigação de conceitos em cegos congênitos. Cadernos Cepre, 1(1), 33-36.

Lewis, M. (1999). Alterando o destino: Por que o passado não prediz o futuro. Campinas: EdUnicamp \& Moderna.

Lewis, V. (2003). Development and disability ( $2^{\mathrm{a}} \mathrm{ed}$.). Oxford, UK: Blackwell.

Lomônaco, J. F. B., Caon, C. M., Heuri, A. L. P. V., Santos, D. M. M. S. \& Franco, G. T. (1996). Do característico ao definidor: Um estudo exploratório sobre o desenvolvimento de conceitos. Psicologia: Teoria e Pesquisa, 12(1), 51-60.

Masini, E. F. S. (1994). O perceber e o relacionar-se do deficiente visual. Brasília: Corde.

Medin, D. L. (1989). Concepts and conceptual structure. American Psychologist, 44(12), 1.469-1.481.

Medin, D. L. \& Smith, E. E. (1984). Concepts and concept formation. Annual Review of Psychology, 35, 113-138.

Murphy, G. L. \& Medin, D. L. (1985). The role of theories in conceptual coherence. Psychological Review, 92(3), 289-316.

Nunes, I. M. (2002). A aquisição de conhecimentos sobre diferentes conceitos em crianças cegas totais com diferentes histórias de vida: Uma investigação. Dissertação de Mestrado, Universidade Federal de São Carlos, São Carlos.

Nunes, S. S. (2004). Desenvolvimento de conceitos em cegos congênitos: Caminhos de aquisição do conhecimento. Dissertação de Mestrado, Universidade de São Paulo, São Paulo.

Ochaita, E. \& Rosa, A. (1995). Percepção, ação e conhecimento nas crianças cegas. Em C. Coll, J. Palácios \& A. Marchesi (Orgs.), Desenvolvimento Psicológico e Educação. (M. A. G. Domingues, Trad.). (pp. 183-197). Porto Alegre: Artes Médicas. 
Oliveira, J. V. G. (1998). Arte e visualidade: A questão da cegueira. Revista Benjamin Constant, 4(10), 7-10.

Oliveira, M. B. \& Oliveira, M. K. (Orgs.). (1999). Investigações cognitivas: Conceitos, linguagem e cultura. Porto Alegre: Artmed.

Ormelezzi, E. M. (2000). Os caminhos da aquisição do conhecimento e a cegueira: Do universo do corpo ao universo simbólico. Dissertação de Mestrado, Faculdade de Educação da USP, São Paulo.

Passos, P. M. P. (1999). A compreensão de metáforas pela criança cega congênita. Cadernos Cepre, 1(1), 26-29.

Piaget, J. (1967). Seis estudos de Psicologia. (M. A. M. D’Amorim, Trad.). Rio de Janeiro: Forense (Originalmente publicado em 1964).

Rosch, E., Simpson, C. \& Miller, S. (1976). Structural bases of typicality effects. Journal of Experimental Psychology: Human Perception and Performance. 2(4), 491-502.
Vygotsky, L. S. (1989). Pensamento e linguagem. (J. L. Camargo, Trad.) ( $2^{\mathrm{a}}$ ed.). São Paulo: Martins Fontes. (Originalmente publicado em 1934).

Vygotsky, L. S. (1996). Obras escogidas, IV. Psicología infantil. (L. Kuper, Trad.). Madrid: Visor. (Originalmente publicado em 1934).

Warren, D. H. (1994). Blindness and children: An individual differences approach. EUA: Cambridge University Press.

Recebido em 21.09.2004

Primeira decisão editorial em 10.02.2005

Versão final em 31.03.2005

Aceito em 11.04.2005 